\title{
ADHESION OF ICE FROZEN FROM DILUTE ELECTROLYTE SOLUTIONS
}

\author{
H.H.G. Jellinek
}

March 1974

\author{
PREPARED FOR \\ U.S. ARMY MATERIEL COMMAND \\ DA PROJECT 1 T061102B52A \\ BY \\ CORPS OF ENGINEERS, U.S. ARMY \\ COLD REGIONS RESEARCH AND ENGINEERING LABORATORY
}

HANOVER, NEW HAMPSHIRE 


\section{PREFACE}

This report was prepared by Dr. H.H.G: Jellinek, Professor of Chemistry, Clarkson College of Technology (USA CRREL Expert). The work was performed under DA Project 1T061102B52A, Mobility and Environmental Research, Task 02, Military Aspects of Cold Regions Research:

The author is indebted to Dr. C.C. Langway, Jr. for his interest in this work.

Manuscript received 7 September 1973. 


\title{
ADHESION OF ICE FROZEN FROM DILUTE ELECTROLYTE SOLUTIONS
}

\author{
by
}

\author{
H.H.G. Jellinek
}

The adhesion of ice has long been studied but a generally satisfactory solution, from the practical standpoint of decreasing adhesion or increasing abhesion, has not yet been found. Complete abhesion can be achieved under laboratory conditions but in practice any surface becomes rapidly contaminated after a few abhesions have taken place and the adhesion of ice continually increases with further abhesions.

Smith-Johannsen ${ }^{7}$ studied the effect of impurities in water on the adhesion of ice by freezing such solutions to various substrates. He ascertained that small initial concentrations. $\left(1 \times 10^{-3}\right.$. mole/liter $(M)$ or less) of electrolytes (salts) decrease ice adhesion considerably. The adhesive strength was measured by the force per square centimeter needed to shear the ice off the substrate. The experiments were carried out at $-10^{\circ} \mathrm{C}$. The freezing point lowering of water by electrolytes of such concentrations is only about $0.005^{\circ} \mathrm{C}$. The ice was frozen rapidly enough so that the electrolyte remained homogeneously distributed throughout the frozen system, and did not have sufficient time to diffuse away from the substrate/solution interface. Air bubbles appeared during the freezing process. Table I gives relevant data $(S=$ salinity of initial solution; $p=$ salınity of grain boundary solution).

Table I. Relevant data for adhesion of $10^{-3} M$ electrolyte solutions frozen to a wax-treated aluminum surface at $-10^{\circ} \mathrm{C}$.

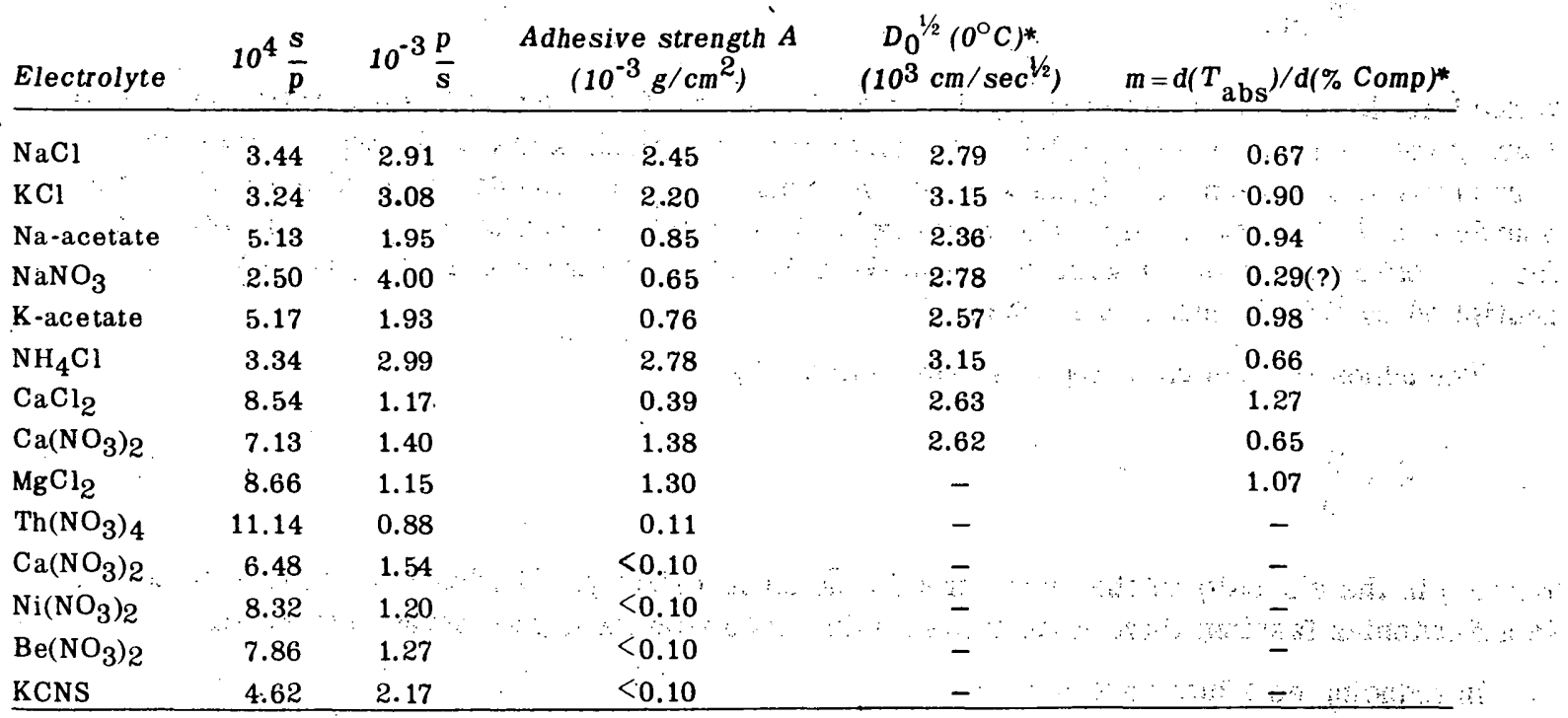

* The diffusion coefficients $D_{0}$ were calculated from the Nernst equation using data from the Handbook of Physics and Chemistry, 48th Edition. Chemical Rubber Publishing Co. The liquidus slopes and $p$ values were derived from data in $A$. Seidall, Solubilities of Inorganic and Metal Organic Compounds, 3rd Edition, D. van Nostrand Co., Inc., 1940. $m$ is the slope of the liquidus curve in the respective phase diagram i.e. $m=d\left(T_{\mathrm{abs}}\right) / d(\%$ Composition $)$. 
The effectiveness of decreasing adhesion, or increasing abhesion, varies considerably with the particular electrolyte in solution. Thus $1 \times 10^{-3} M \mathrm{Th}\left(\mathrm{NO}_{3}\right)_{4}$ decreases adhesion by $97 \%$ on a waxtreated aluminum surface, whereas the same molar concentration of $\mathrm{NaCl}$ causes a decrease of only 42\%. The term adhesion is not used here in its strict sense, i.e. a break in the substrate/ice interface; any breaks very near the interface are included in this term.

With a few exceptions, the total salt concentration eventually has to accumulate in grain boundaries when such a solution freezes; the concentration of the electrolyte is practically zero in the lattice of the ice grains. The grain boundary consists of a saturated solution in accordance with the phase diagram of the respective electrolyte, provided the temperature is above the eutectic temperature. The width of the grain boundary can be calculated if the phase diagram is known; this has been done, for instance, by Chatterjee and Jellinek ${ }^{2}$ for $\mathrm{NaCl}$ solutions.

Smith-Johannsen ${ }^{7}$ pointed out that effective electrolytes should have endothermic heats of solution,* low eutectic temperatures and appreciable solubility at $0^{\circ} \mathrm{C}$." If the solution is frozen below the eutectic temperature, then the adhesion increases considerably.

It is of interest to consider the possible conditions at or near the substrate/ice interface. This may give a clue as to the mechanism of the reduction of adhesion by electrolytes initially present in dilute solutions. If it is assumed that a thin liquid solution layer is formed between the ice and substrate, then the ice could be relatively easily sheared off the substrate. The shear force per square centimeter or the adhesive strength would depend on the thickness and viscosity of the layer and the rate of shear. The formation of such a layer is assumed to be subject to the same laws as the formation of grain boundaries but the layer would not necessarily be of similar thickness. The latter may also be a function of the nature of the substrate.

The width or thickness $\delta$ of a grain boundary for prismatic ice grains of quadratic cross section is given by $^{2}$

$$
\delta=\frac{\mathrm{s} \rho_{\mathrm{i}, \mathrm{T}} \overline{\mathrm{b}}}{2 \boldsymbol{p} \rho_{\mathrm{gb}, \mathrm{T}}} \quad(\delta<<\overline{\mathrm{b}})
$$

where $\bar{b}$ is the average width of the grains, i.e the length of the edge of the quadratic cross section, $s$ and $p$ are the salinities (in $g / 1000 \mathrm{~g}$ of solution) of the initial solution and the saturated grain boundary solution, respectively, at $T \mathrm{~K}$, and $\rho_{\mathrm{i}, \mathrm{T}}$ and $\rho_{\mathrm{gb}, \mathrm{T}}$ are the densities of ice and the grain boundary at $T$. K, respectively. The width for an interfacial solution layer can be multiplied by a factor to take care of the characteristics of the substrate. The right side of eq 1 has to be multiplied by $2 / 3$ if the grains are spherical.

The adhesive strength $\boldsymbol{A}$ for this case is given by

$$
A=\frac{\eta v}{\delta}
$$

where $\eta$ is the viscosity of the layer and $v$ is the shear velocity. The layer is assumed to behave in a Newtonian fashion; there is no evidence that such solution layers behave otherwise.

Introducing eq 1 into eq 2 yields

$$
A=\frac{2 \eta v \rho_{\mathrm{gb}, \mathrm{T}}}{\rho_{\mathrm{i}, \mathrm{T}} \bar{b}} \cdot \frac{p}{\mathrm{~s}}
$$

*It is doubtful that this is necessary; the adhesion value for $\mathrm{FeCl}_{3}$, which has an exothermic heat of solution, fits the value for $\mathrm{HCl}$ well. $\mathrm{FeCl}_{3}$ is practically completely hydrolyzed. 


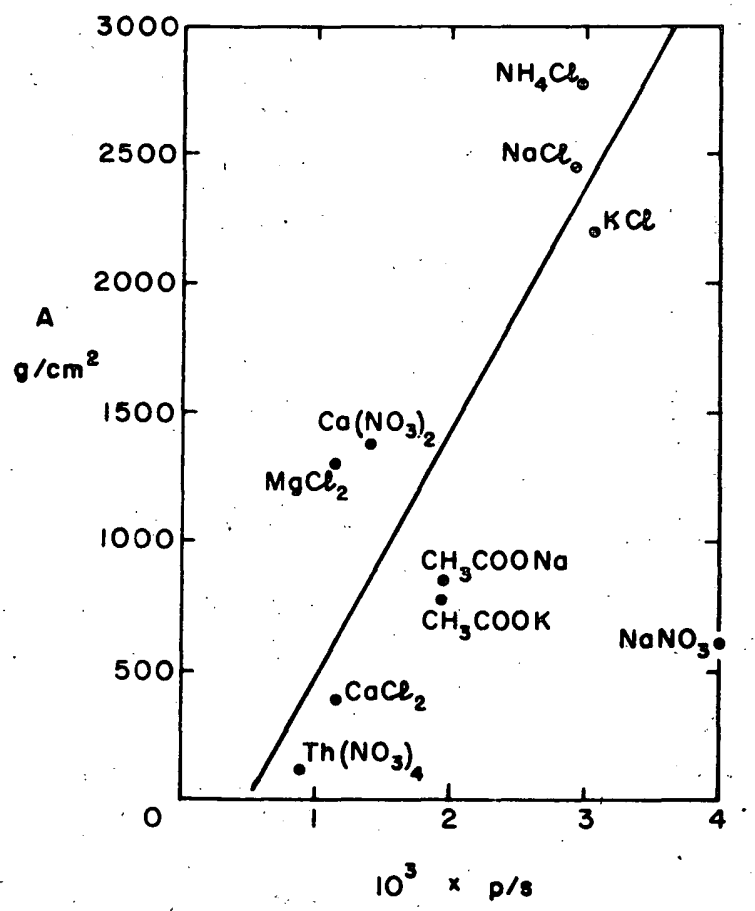

Figure 1. Adhesive strength versus ratio of salinities in grain boundaries to those in initial solutions $\left(-10^{\circ} \mathrm{C}, 10^{-3} \mathrm{M}\right.$ solutions).

The ratio $\rho_{\mathrm{gb}, \mathrm{T}} / \rho_{\mathrm{i}, \mathrm{T}}$ and the viscosity $\eta$ vary relatively little with the nature of the electrolytes and their concentrations; $\bar{b}$ depends mainly on the rate of freezing, and $v$ and $T$ are kept constant. Hence, the adhesive strength will be predominantly influenced by the ratio $p / s$. Equation 3 can then be simplified to

$$
A=K \frac{p}{\mathrm{~s}}
$$

where $K$ is a constant. Figure 1 shows $A$ plotted versus $p / s$ using data from Table I. Equation 4 is as well obeyed as can be expected under the circumstances. All solutions were initially $1 \times$ $10^{-3} . M$. Hence, in order to obtain $s$ in $\mathrm{g} / 1000 \mathrm{~g}$ of solution, the molarity has to be multiplied by the molecular weight of the respective electrolyte. The straight lines and all subsequent ones have been drawn by the method of least squares.

However, this situation at the interface considered above is not the only one which can be visualized. The ice prisms could be directly frozen with their quadratic cross sections to the substrate. These prisms would then be separated from each other by grain boundaries of width $\delta$ according to eq 1 . The adhesive strength in this case can be assumed to be given by the force per square centimeter needed to rupture by shear the ice prisms contained in $1 \mathrm{~cm}^{2}$ of interface, hence

$$
A=A_{0}(\mathrm{a} Y)^{2}
$$

where $A_{0}$ is the force necessary to rupture ice with an actual cross section of $1 \mathrm{~cm}^{2}, a$ is the number of prismatic grains along $1 \mathrm{~cm}$ in the frozen system, and $Y^{2}$ is the cross-sectional area of 


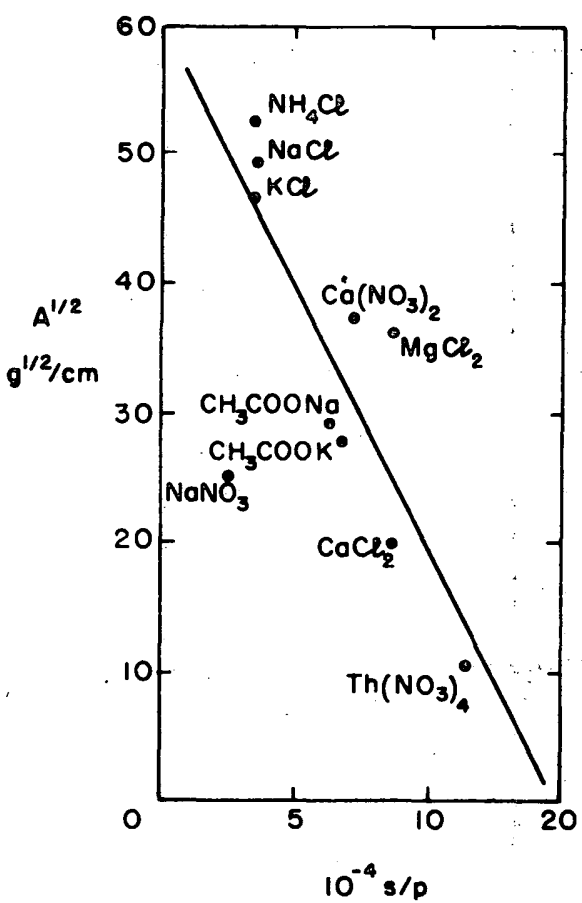

Figure 2. Square root of adhesive strength versus ratio of initial to grain boundary salinity. one prism. It has to be noted that all dimensions are average quantities in this context. The term $(a Y)^{2}$ is equal to the fraction of $1 \mathrm{~cm}^{2}$ occupied by the prisms, i.e. it is a pure number.

$Y$ can easily be related to $\delta$, the width of the grain boundary:

$$
a Y+(a-1) \delta \cong a(Y+\delta)=1
$$

Hence, introducing $\delta$ from eq 6 into eq 5 gives

$$
A=A_{0}(1-\mathbf{a} \delta)^{2}
$$

Further, introducing eq 1 into eq 7 , assuming again that all parameters except $p$ and $s$ vary little, yields

$$
A=A_{0}\left(1-K, \frac{\mathrm{s}}{p}\right)^{2}
$$

Hence, $A^{1 / 2}$ plotted versus $s / p$ should result in a straight line. This is as satisfactorily the case as in the previous instance (see Fig. 2).

However, a difficulty arises here. The grain boundary and the interfacial layer widths are quite small, hence even doubling the grain boundary width should decrease the adhesive strength by only a small amount. However, in actual fact the decreases in adhesive strength are quite large. Hence, eq 5 or 7 , respectively, cannot be correct.

Equation 7 should rather be of the form

$$
A=A_{0}\left(1-\mathrm{a}^{\mathrm{n}} \delta\right)^{2}
$$

where the exponent $n$ is larger than one. This results in the following functional relation between $A$ and $Y$ :

$$
A \doteq A_{0}\left[1+\mathrm{a}^{\mathrm{n}-1}(\mathrm{a} Y-1)\right]^{2}
$$

Equation 9 can also be expressed as

$$
A=A_{0}\left(1-\frac{\nu^{k}}{h^{1 / 2}}\right)^{2}=A_{0}\left(1-\frac{a^{n} \nu^{1 / 2}}{h^{1 / 2}}\right)^{2}
$$

where $\nu$ is the volume of the grain boundaries between prisms of height $h$. Equation 10a is one of the forms for the strength of salt ice. ${ }^{4}$ Equation 8, however, is still valid with a larger value of $K^{\prime}$.

There are still some other possibilities which have to be considered. It is known that dendrites are formed at the solution/ice interface during freezing of salt solutions. It could be assumed that 


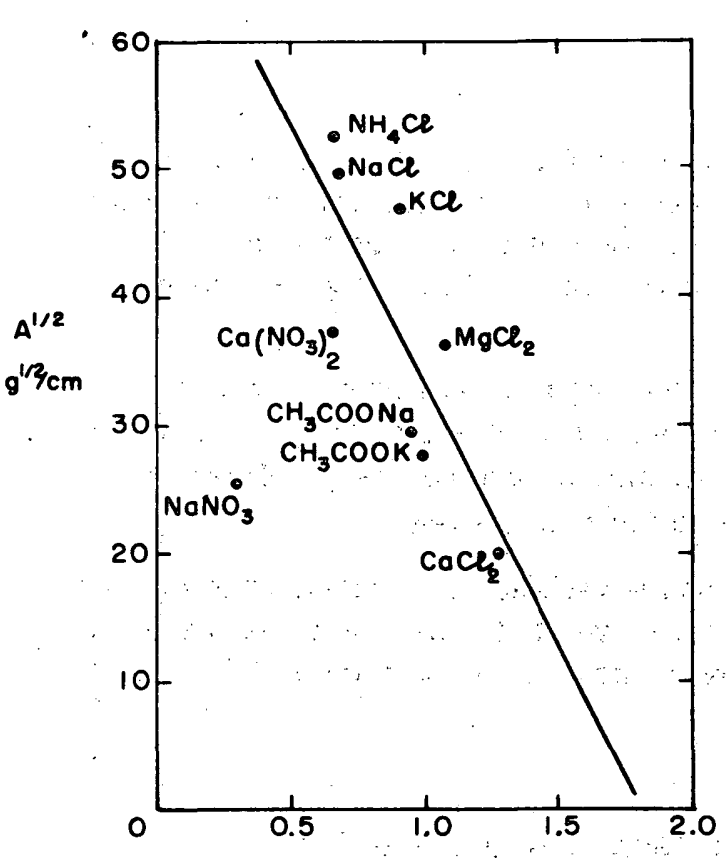

m

Figure 3. Square root of adhesive strength versus slope of liquidus curve of phase diagram.

small dendrites also grow from solid surfaces under suitable conditions. Camp ${ }^{1}$ has shown that dendrites grow from solid surfaces if the temperature is low enough. French ${ }^{3}$ has deduced the conditions for dendrite growth at the solution/ice interface. If his theory is applied to the solid/ice interface (whether this is permissible is doubtful) then the dendrite : spacing $L$, i.e. the distance between the centers of two adjacent dendrites, can be calculated. The relevant expression is

$$
L=\frac{4 \Delta T \sqrt{D_{0} \theta_{\mathrm{f}}}}{C_{0} \sqrt{\pi}}
$$

where $\Delta T$ is the extent of supercooling (for details see reference 3$), D_{0}$ is the diffusion coefficient of the electrolyte, $\theta_{f}$ the freezing time, and $C_{0}$ the initial molality of the solution. Further, French ${ }^{3}$ derived that

$$
\Delta T=-m C_{0} \beta \sqrt{\pi}
$$

where $m$ is the slope of the liquidus curve in the respective phase diagram (this slope is negative) and $\beta$ is a constant. Hence, introducing eq 12 into eq 11 gives

$$
L=-4 m \beta \sqrt{D_{0} \theta_{\mathrm{f}}}
$$

$D_{0}$ varies very little compared with $m$. If dendrites are assumed to have the shape of quadratic prisms, then the adhesive strength is again given by eq 10. $L$ is related to $Y$ as follows:

$$
(a-1) L+Y=1
$$

Hence eq 5 gives

$$
A=A_{0} \mathrm{a}^{2}[1-(\mathrm{a}-1) L]^{2}
$$

Introducing eq 13, assuming everything to be constant except $L$, gives

$$
A=A_{0} \mathrm{a}^{2}\left(1+K^{\prime \prime} \mathrm{m}\right)^{2}
$$

The same difficulty arises here as in the previous case. $L$ is very small and the decrease of $A$ with $L$ is much greater than is possible for small values of $L$. Hence $(a-1)$ can be raised to a power $n$; this does not affect eq 16 except for the magnitude of $K^{\prime \prime}$. Equation 15 then becomes

$$
A=A_{0} \mathrm{a}^{2}\left[1-(\mathrm{a}-1)^{\mathrm{n}-1}(1-Y)\right]^{2}
$$

$A^{1 / 2}$ plotted versus $m$ again gives a satisfactory straight line (see Fig. 3).

Rohatgi and Adams $^{6}$ made calculations similar to those of French. ${ }^{3}$ Their results can be expressed by an equation as follows: 


$$
L^{2}=8 D \frac{p}{s} \frac{d \theta}{d t s}
$$

where $d \theta / d t s$ is the reciprocal rate of freezing ( $f s=$ fraction of solid). Equation 18 leads to a contradiction. It indicates that $L^{2}$ increases with $p / s$; in other words $\delta$ decreases with increasing values of $\mathrm{p} / \mathrm{s}$, which contradicts eq 1 . Equation 18 can only become consistent with eq 1 if $d \theta / d t s$ changes so that the increase in $p / s$ is more than compensated. This inconsistency has already been pointed out by Lofgren and Weeks ${ }^{5}$ ).

Thus, the above discussion shows clearly that the variations in grain boundary or in interfacial solution layer thickness are mainly responsible for the variations in adhesive strength. However, a decision cannot be made on the basis of the above considerations whether ice (dendrites or prisms) is ruptured or whether an interfacial liquid solution layer is sheared.

Smith-Johannsen ${ }^{7}$ also performed some experiments on the variation of adhesive strength with solute concentration. The results of these experiments give clues to the mechanism of the adhesion process. Table II gives adhesion values as a function of solute concentration for $\mathrm{Th}\left(\mathrm{NO}_{3}\right)_{4}$ and $\mathrm{Ca} \mathrm{Cl}_{2}$ solutions.

Table II. Effect of salt concentration on adhesive strength $\left(-10^{\circ} \mathrm{C}\right) .^{?}$

\begin{tabular}{ccc}
$\begin{array}{c}\text { Conc } \\
(\mathrm{mol} / \mathrm{l})\end{array}$ & $\begin{array}{c}\text { Adhesive } \\
\text { strength } \mathrm{A} \\
\left(\mathrm{g} / \mathrm{cm}^{2}\right)\end{array}$ & $\begin{array}{c}\text { Change in } \\
\text { adhesive strength } \\
(\%)\end{array}$ \\
\hline $\mathrm{Th}\left(\mathrm{NO}_{3}\right)_{4}$, & wax-treated aluminum surface \\
0 & 4250 & 0 \\
$1 \times 10^{-5}$ & 3225 & 25 \\
$1 \times 10^{-4}$ & 1990 & 53 \\
$4 \times 10^{-4}$ & 1075 & 74 \\
$1 \times 10^{-3}$ & 110 & 97 \\
\multicolumn{4}{c}{$\mathrm{C}_{2} \mathrm{Cl}_{2}}$, & clean aluminum surface \\
0 & 8000 & 0 \\
$1 \times 10^{-4}$ & 3300 & 59 \\
$7 \times 10^{-4}$ & 1800 & 78 \\
$1 \times 10^{-3}$ & 1600 & 81 \\
$2.5 \times 10^{-3}$ & 1100 & 87 \\
$5 \times 10^{-3}$ & 480 & 94 \\
$1 \times 10^{-2}$ & 130 & 98
\end{tabular}

$A$ plotted versus concentration gives curves which show very rapid initial decreases in adhesive strength with increasing electrolyte concentrations, which eventually slow down, resulting in straight lines with moderate slopes at concentrations near $5 \times 10^{-4} \mathrm{M}$. Plots of $A^{1 / 2}$ versus concentration still show appreciable curvatures, as do plots of $A$ versus reciprocal concentration.

The plot of $A$ versus reciprocal initial concentration should result in a straight line according to eq 3 . Neither are eq 8 and 15 obeyed; the latter should be taken in conjunction with eq 11 . The deviations from straight lines according to eq 8 , which has been derived on the assumption that ice prisms are ruptured, can, in principle, be accounted for by the known fact that the number of defects, 
i.e. dislocations or impurities in the ice lattice, in an ice prism decreases with its size (in this case with the grain size). This could result in deviations from a straight line of a plot of $A$ versus concentration as indicated by the experimental data. Also the experimental results evaluated by eq 14 in conjunction with eq 11 show deviations in the right direction.

Adhesive strength due to the interfacial liquid solution layer should be a linear function of the reciprocal initial concentration; however, as already indicated above, such plots have a very pronounced curvature, especially in their initial parts. The thickness of such layers over the whole range of concentrations. is actually very small. Thus, it is conceivable that the roughness of the substrate surface will strongly influence the sliding of the ice across the substrate surface due to shear forces. This was found to be the case with thin water layers. 4 Sliding of glaciers promoted by an interfacial water film is also of interest in this connection. ${ }^{10}$. Actually, the reciprocal sliding velocity as a function of water layer thickness between the ice and the bed of a glacier gives curves similar to plots of adhesive strength versus concentration observed by Smith-Johannsen.? It is difficult to see why the whole base of the ice prism should be frozen directly to the substrate. There is no reason to suppose that grain boundaries should not also exist between the prism and the substrate. Thus it seems more likely that an interfacial liquid solution layer is sheared than that ice prisms, directly frozen to the substrate, are ruptured.

The overall conclusion reached is that the variation of adhesive strength due to a number of electrolytes in dilute solutions is in large part due to the shearing of an interfacial liquid solution layer which is formed during freezing. The thickness of such a layer may be influenced by the nature of the substrate. This thickness is mainly proportional to the ratio of the salinity of the initial solution to the salinity of the saturated solution in the grain boundary. In addition, equimolar solutions do not have identical initial salinities in terms of $\mathrm{g} / 1000 \mathrm{~g}$ of solution; the molarity has to be multiplied by the molecular weight of the respective electrolyte. If the temperature of the icesubstrate system lies below the eutectic point of the electrolyte, then the adhesive strength is appreciably increased compared with that for a temperature above the eutectic one.

The thickness of the interfacial layers is so small for the range of $10^{-5}$ to about $10^{-3} \mathrm{~mol} / \mathrm{liter}$ of initial electrolyte concentrations that the roughness of the substrate surface has an appreciable frictional effect on the sliding velocity of the ice across the substrate surface.

Although it cannot be concluded with certainty that the above mechanism is the one which is actually realized, it appears to be the most reasonable of the possibilities that present themselves. Confirmation of this mechanism could be obtained experimentally by freezing dilute electrolyte solutions to optically flat plates and observing the sliding velocity as a function of shear force.

\section{Literature cited}

1. Camp, P.R. (1965) The formation of iee at water solid interfaces. Ann. N.Y. Acad. Sci., vol. 125 , p. $317-343$.

2. Chatterjee, A.K. and H.H.G. Jellinek (1971) Caleulations of grain-boundary thickness in polycrystalline ic e of low salinity. Journal of Glaciology, vol. 10, p. 293-297.

3. French, D.N. (1962) Solidification of aqueous solutions. Ph.D. Thesis, Department of Metallurgy, MIT:

4. Jellinek, H.H.G (1960) Some frictional properties of thin water films. U.S. Army Snow; Ice and Permafrost Research Establishment (USA SIPRE) Special Report 37.

5. Lofgren, G. and W.F. Weeks (1969) Effect of growth parameters on substructure spacing in NaCl-ice crystals. Journal of Glaciology, vol. 8, p. 153-164. 


\section{LITER ATURE CITED (cont'd)}

6. Rohatgi, P.K. and C.M. Adams (1967) Ice-brine dendritic aggregate formed on freezing of aqueous solutions. Journal of Glaciology, vol. 6, p. 663-679.

7. Smith-Johannsen, R. (1946) Effect of impurities in water on ice adhesion. General Electric Company Report 5539; Pts. I and II, p. 149-191 (ATSC Contract W-33-038-AC-9151).

8. Weeks, W.F. and A. Assur (1963) Structure control of the vertical variation of the strength of sea and salt ice. In Ice and Snow (W.D. Kingery, Ed.). Cambridge, Mass.: MIT Press, p. 258-276.

9. Weertman, J. (1964) Glacier sliding. U.S. Army Cold Regions Research and Engineering Laboratory (USA CRREL) Research Report 162.

10. Weertman, J. (1969) Water lubrication mechanism of glacier surges. Canadian Journal of Earth Science, vol. 6, p. 929-942. 
Security classification of title, body of abstract and indexine ennotallon must be entered when the overall report is clasaltied) OFIGINATING ACTIVITY (Corporate euthor)

U.S. Army Cold Regions Research and Engineering Laboratory

Hanover, New Hampshire 03755

4. REPOAT TITLE

\section{ADHESION OF ICE FROZEN FROM DILUTE ELECTROLYTE SOLUTIONS}

4. DESCRIP IIVE NOTES (TyPe of report and incluaive datea)

5. AUTHORISI (First name, middlo initial, last namo)

H.H.G. Jellinek

\begin{tabular}{|c|c|}
\hline $\begin{array}{l}\text { C. REPOKT OATE } \\
\text { March } 1974\end{array}$ & $\begin{array}{l}\text { 79. TOTAL NO. OF PAGES } \\
10\end{array}$ \\
\hline OA. OONTAACT ORGRAISTNO. & 90. ORIGINATOR'S REPORT MUMBEERIS) \\
\hline $\begin{array}{l}\text { t. WR'JUECT NO. } \\
\qquad \text { DA Project } 1 \mathrm{~T} 061102 \mathrm{~B} 52 \mathrm{~A}\end{array}$ & Research Report 317 \\
\hline $\begin{array}{l}\text { c. } \\
\text { c. }\end{array}$ & $\begin{array}{l}\text { 0b. OTHER REPORT NO(S) (Any cther numbers that may bo asalenod } \\
\text { thie roport) }\end{array}$ \\
\hline
\end{tabular}

Approved for public release; distribution unlimited.

\begin{tabular}{l|l}
\hline 1 SUPPLEMENTARY NOTES & $\begin{array}{l}\text { 12. SPONSORING MILITARY ACTIVITY } \\
\text { U.S. Army Materiel Command }\end{array}$
\end{tabular}

13. A.BSTRACT

Experiments by Smith-Johannsen on the adhesion of ice frozen from a number of $1 \times 10^{-3} \mathrm{M}$ electrolyte solutions to a wax-treated aluminum surface at $-10^{\circ} \mathrm{C}$ are discussed. It is concluded that the adhesive strength measured by the force per square centimeter needed to shear the ice off the substrate surface is mainly due to a liquid interfacial solution layer between the ice and the substrate surface. The thickness of such a layer is largely determined by the same considerations as the thickness of grain boundary layers in ice obtained from dilute electrolyte solutions.

14. Key Words
Abhesion
Adhesion
Adhesive strength
Deicing
Freezing of electrolyte solutions
Grain boundary solution layers
Ice control
Ice formation 